\title{
GENÇLER NEDEN SNAPCHAT KULLANIYOR KULLANIMLAR VE DOYUMLAR YAKLAŞIMI ÜZERINDEN BİR ARAŞTIRMA
}

\author{
Why Young People Use Snapchat? A Uses And Gratifications Approach
}

\author{
Doç.Dr. Tolga KARA ${ }^{1}$ \\ Marmara Üniversitesi, İletişim Fakültesi \\ Medya Ekonomisi ve İşletmeciliği A.B.D. \\ İstanbul
}

\begin{abstract}
Özet: Bugün geldiğimiz noktada, sosyal medyanın kullanım biçimi, kullanım aralıkları ve araçların değişen kullanım alışkanlıkları toplumsal hayatın dönüştüğünü ortaya koymaktadır. 1950'li yılların sonunda ise Katz ve arkadaşları, bireylerin kitle iletişim araçlarını seçerken kimi ihtiyaçlarını karşılamayı gözettikleri fikrini ortaya atmışlardır. Bugün teknolojinin gelişmesi ile birlikte kullanılan araçlar değişmiş fakat birey ihtiyaçları aynı kalmıştır. Bu fikirden hareketle, günümüzün sosyal medya araçları da kimi bireylerin kimi intiyaçlarını doyuracak biçimde tercih ediliyor olabilir. Dolayısıyla insanların belirli sosyal medya araçlarını neden tercih ettiği ve bu tercihlerin kullanıcıların hangi ihtiyaçlarını karşıladığı soruları karşımıza çıkmaktadır. Bu çalışma, üniversite öğrencisi gençlerin günümüzün popüler sosyal medya uygulamalarından biri olan Snapchat'i ne amaçla kullandığını Kullanımlar ve Doyumlar Teorisi bağlamında incelemeyi amaçlamaktadır. Bu amaçla, basit tesadüfi örnekleme yöntemiyle belirlenen Marmara Üniversitesi Illetişim Fakültesi öğrencileriyle odak grup görüşmeleri gerçekleştirilmiş ve Snapchat kullanım tercihleri, kullanım nedenleri, paylaşım sıklıkları, içerikleri ve erişim araçlarına yönelik açık ve kapalı uçlu sorular sorulmuştur. Elde edilen yanıtlar, Korgaonkar ve Wolin'in (1999) belirlediği sosyal etkileşim, bilgi arama/bilgiye ulaşma/bilgi paylaşma, zaman geçirme, eğlence, rahatlama, düşüncelerin ifadesi, kullanım kolaylığı, gözetim, beğenilme/takdir edilme doyum sınıfları bağlamında değerlendirilmiştir.
\end{abstract}

Anahtar Kelimeler: Sosyal Medya, Kullanımlar ve Doyumlar, Snapchat

Extended Abstract: At the point we have reached today, usage style, frequency and tools of social media reveals that to the return of social life. At the end of the 1950s, Katz and his partners found that individuals thought they could meet their needs when choosing mass media. Today, with the development of technology, the tools used have changed, but the needs of individuals have remained the same. In that case, today's social media tools may be preferred in ways that will satisfy some individuals' needs. Therefore, the question of emerged that why people prefer some social media tools and which social needs satisfied by this social media tools. This study aims to analyze why university students use the today's one of the most popular social media app snapchat in the context of Uses and Gratifications theory. For this purpose, focus group interviews were conducted with Marmara University Communication Faculty students determined by simple random sampling method and open and closed questions were asked about Snapchat usage preferences, usage reasons, sharing frequencies, contents and access tools. Answers were evaluated in the context of Korgaonkar and Wolin's (1999) satisfaction categories which is social interaction, information seeking / information sharing, time spent, leisure, relaxation, expression of feelings, ease of use, surveillance, appreciation / appreciation saturation.

\footnotetext{
${ }^{1}$ tolgakara@marmara.edu.tr
} 
A Uses And Gratifications Approach has been developed against the passive perception of the viewer within the theories of mass communication effects. The approach suggests that viewers are in conscious preferences and use media for this purpose. Therefore, according to the Uses and Satisfaction Approach, people consume the media according to their needs. The needs of the viewer determine how and for what purpose media content is consumed.

Researchers working on the use and gratifications approach have generally focused on classifying human needs. The most detailed classification of the subject can be seen in the work of Blumler, McQuail and Brown. According to Blumler, McQuail and Brown, the basic need categories are entertainment, personal relationships, personal identity and surveillance. Researchers have examined what masses makes to gratifications these.

The internet has created a landscape ripe for innovative forms of social media in recent years-some of which allow for far greater levels of both mass and interpersonal communication than others. Social media are similar to Boyd and Ellison's (2007) definition of social networking sites, which are "web-based services that allow individuals to construct a public or semi-public profile within a bounded system, articulate a list of other users with whom they share a connection, and view and traverse their list of connections and those made by others within the system." The social networks and the emergence of social media and their popularity have made it easier for thousands of people to communicate with each other as a single individual. On the other hand, social networking sites can classify and label by considering criteria such as age, religion, political opinion, hobbies and interests. With this classification and labeling, it is possible to investigate how interactions between groups. Therefore, when social media application has changed, the target audience and usage model will changed too. Snapchat, which constitutes the subject of this work, has a number of differences in its nature, usage and algorithm. But it is consistent with the general characteristics of social media platforms.

Snapchat was founded in 2011 by three Stanford University students, Evan Spiegel, Bobby Murphy and Reggie Brown, and is a privacy-based mobile sharing application that allows time-limited photo / video sharing among friends. The main difference that distinguishes the application from similar ones is that users can determine how long they can be displayed on the other side of the video or photos that are captured and called "snap". The application, which allows viewing for up to 10 seconds, finally deletes the images and notifies the content owner if any screen images are taken and application allows you to send snapshots both individually and collectively. Users can create snap clusters called "stories" to share photos and videos in a way that all viewers can see. On the other hand, users can make their sharing fun with some add-ons or they can send text messages to each other with the help of private messaging service. Snapchat's display and voice communication capabilities are a typical social media platform with the promise of usage and entertainment that can be considered relatively safe. On the other hand, the most important feature of Snapchat that separates social media from other traditional media is that users are able to actively engage in content creation and interact and it allows users to turn into "prosumer".

This study aims to examine the Snapchat application in the context of the Uses and Gratifications Approach. The reason why this study is conducted with youngsters is the fact that young people use social media more actively. With such an aim, the main starting point of the study is detecting the relationship between social media app and social life.

Keywords: Social Media, Uses and Gratifications, Snapchat

\section{GíRiş}

Illk insandan günümüze kadar geçen süreç içinde tüm toplumun iletişime olan ihtiyacı değişmezken, iletişim kurma becerileri sıklıkla değişmiştir. Bu değişimin temel dinamikleri arasında teknolojik gelişim önemli bir rol oynamaktadır. Gelişen iletişim teknolojileri yıllar içinde insanların iletişim kurma becerilerinde önemli değişimler yaratmıştır. Teknolojiye paralel olarak insanların bu araçları kullanım biçimleri ve nedenleri de değişime uğramıştır. İnsanoğlu, kimi araçlardan elde edilen fayda ve doyum gündelik ihtiyaç ve beklentinin altında kaldığında bu araçlardan vazgeçmiş, ihtiyaçlarını karşılayan ve beklentilerine cevap veren yeni araçlar geliştirmiştir. 
Günümüzde insanlar iletişim kurmak, gündemi takip etmek vb amaçlarla ilk çağdaki atalarından farklı yöntem ve araçlar kullanmaktadır. Geleneksel iletişim yerini zamanın ve mekanın yeniden tanımlandığı dijital temelli ortamlara bırakmıştır. Bugün yeni medya çağı olarak adlandıılan bu dönemin ortaya çıkardığı en önemli özellik etkileşim ve zaman/mekan kısıtlarının ortadan kalkmasıdır. Yeni medya, insan-mekan ilişkilerini değiştirmiş, fiziksel ve toplumsal alanı birbirinden ayırmış ve sosyal kimlikleri yeniden biçimlendirilmiştir. Böylece yüzyüze ilişkilerin esas olduğu toplum yerini, bireyin mekansal kısıtlardan özgürleştiği yeni bir toplum tipine bırakmıştır (Timisi, 2003, 28). Ortamın değişimi beraberinde onu kullanan kullanıcıyı da yeniden biçimlendirmiştir. McLuhan'ın fazlasıyla determinist araç mesajdır yaklaşımından da anlaşılacağı üzere; kullanıcıların algı, tutum, düşünce ve davranışları da yeni medyanın araçsal temelinde yeniden tanımlanmaya başlamıştır (Rigel, v.d., 2005, 142). Yeni medyanın yeni kullanıcısı sadece içeriğe maruz kalmak yerine alternatif içerik üreten, etkileşimli, eleştirel ve mekandan bağımsız kişilerdir.

Yeni medya teknolojileri ve web 2.0 altyapısında gelişen sosyal medya ise bireysel ve toplumsal iletişim biçimlerinin son halkasını oluşturmaktadır. Sosyal medya kullanıcılarına anlık olarak diğer kullanıcılar ile düşüncelerini, fikirlerini tartışabilme, duygularını ortaya koyabilme, kişisel bilgilerini, fotoğraflarını, videolarını dijital platformlarda paylaşabilme imkan tanımaktadır. Bu haliyle geleneksel iletişim biçimlerine oranla yepyeni ve alışılmadık bir kullanıcı deneyimi sunan sosyal medya'nın kullanım nedenleri, motivasyonları, oluşturduğu alışkanlık ve tercihler ile hangi kullanıcı ihtiyaçlarını giderdiği ve ne gibi bir doyum sağladığı da araştırılması gereken önemli sorular haline gelmiştir.

Kullanımlar ve Doyumlar yaklaşımı ile sosyal medya ilişkisine dair yerli ve yabancı literatür incelendiğinde sosyal medyanın erken dönemlerinde gerçekleştirilmiş ve alana farklı uygulamalar penceresinden bakan çalışmaların varlığı görülmektedir. Bunlardan en dikkat çekici olanları arasında Alikılıç, Gülay ve Binbir (2013), Charney ve Greenberg (2001), Chou ve Hsiao (2000), Eighmey ve McCord (1998), Raacke ve Bonds (2008), Kaye ve Johnson (2002) ve Namsu Park ve arkadaşlarının (2002) çalışmaları sayılabilir.

Bu çalışma özellikle 90 sonrası doğumlu ve Y kuşağının sonlarını temsil eden, echoboomers ya da nexters olarak adlandırılan bilgisayar, cep telefonu ve internetin yaygın biçimde kullanıldığı bir dönemde büyüyen ve bu teknolojileri hayatına entegre etmiş gençlerin sosyal medya tercihlerinin nedenlerine ve sonuçlarına odaklanmaktadır. Bu noktadan hareketle Marmara Üniversitesi İletişim Fakültesi son sınıf öğrencilerinin sosyal medya uygulamalarındaki tercihlerinin nedenlerine ilişkin niteliksel bir araştırma tasarlanmış, söz konusu kriterlere uyan öğrencilerin platform tercihleri ve buradan elde ettikleri doyumlar son dönemdeki popüler sosyal medya uygulaması olan Snapchat özelinde değerlendirilmeye çalışılmıştır. Araştırmada gençlerin Snapchat uygulaması kullanımında elde ettikleri temel doyumun eğlence arayışının tatmin edilmesi olduğu, öte yandan diğer kullanıcıların gündelik yaşamlarını takip etmenin de bir diğer önemli doyum noktasını oluşturduğu tespit edilmiştir.

\section{KULLANıMLAR VE DOYUMLAR YAKLAŞıMı: KURAMSAL ÇERÇEVE}

İletişimin bir bilim olarak araştırılmaya başladığı dönemlerdeki en yaygın konulardan birisi de kitle iletişim araçları (KIA) ile kullanıcı arasındaki ilişkidir. Pek çok araştırmacı kitle iletişim araçlarının kitleler üzerindeki etkilerini ölçmeye çalışmış ve çeşitli teoriler geliştirmiştir. Devlet ve özel sektör vakıflarınca sıklıkla desteklenen bu araştırmalara göre güçlü ve sınırlı etkileri olduğuna dair iki farklı görüş ortaya atılmıştır. Yapılan ilk çalışmalar KíA'ların kitleler üzerinde çok güçlü etkileri olduğunu ortaya koyar niteliktedir. Özellikle Hipotermik iğne, Sihirli Mermi gibi isimlerle anılan bu teoriler bireylerin, kitle iletişim araçları tarafından yollanan mesajlara karşı pasif, edilgen, savunmasız, etkiye açık olduğu düşüncesi etrafında şekillenmektedir. Bu ilk dönem yaklaşımlara göre 
kitle iletişim araçlarını kontrol edenler toplumun genelini de kontrol etmektedir (Edoğan ve Alemdar, 2010, 54). Fakat zaman içinde bu yaklaşımların KiA ve kitle arasındaki ilişkiyi açıklamakta yetersiz kaldığı görülmüştür. Kullanıcıların aldıkları eğitim, bulundukları çevre, sahip oldukları zeka düzeyi ve bilgi birikimi gibi özelliklerinin medya mesajlarını algılama ve onlardan etkilenme konusunda rol oynadığı fikri üzerinden yeni çalışmalar ortaya çıkmış ve kullanıcıların KíA’lar üzerinde etkin rol oynadıkları düşüncesi ağır basmıştır.

1940’Iı yıllara gelindiğinde araştırmalarda izleyicinin araç karşısındaki nesne konumundan özne konumuna getirildiği görülmektedir. 1950'lerin ortalarından itibaren araç merkezli araştırmalardan izleyici merkezli araştırmalara kayılmasıyla birlikte, kullanıcıların kitle iletişim araçları ile ne yaptığı ve ne yapmak istediği daha fazla önem taşımaya başlamıştır. Bu çalışmaların temelindeki düşünce, bireylerin belirli ihtiyaçlarını karşılamak için belirli KiA’lara yöneldikleri etrafında şekillenmektedir (Defflour ve Dennis, 2002, 99). Bu düşünceden filizlenen en önemli yaklaşımlardan bir tanesi de Kullanımlar ve Doyumlar Yaklaşımı́dır.

Kullanımlar ve doyumlar yaklaşımı, kitle iletişim etki kuramları içinde izleyicinin pasif olarak algılanmasına karşı geliştirilmiştir. Yaklaşım, izleyicinin kitle iletişim araçlarında yer alan verileri medyanın onun isteği doğrultusunda değerlendirdiği söylemi yerine, izleyicilerin birçok kez önceden karar vererek bazense daha az planlı olmak üzere bilinçli olarak tercihlerde bulunduklarını ve bu doğrultuda medyayı kullandığını ileri sürmektedir (Hermes 2002: 283). Psikolojik etki kuramları arasında sayılan kullanımlar ve doyumlar yaklaşımın öncüleri 1940'lı yılların başlarına kadar gitmektedir. 1942 ve 1944 yılları arasında Lazerfeld ve Herzog radyo dinleyicilerinin hangi ihtiyaçlarını doyurmak için hangi kanalları dinlediklerini araştırarak alanda öncü olmuşlardır (Jensen \& Rosengren, 2007:55). Yıllar içinde giderek evrilen araştırma süreci 1959 yılında Katz'ın önderliğinde medyanın insanlara ne yaptığından ziyade insanların medyayla ne yapmak istediklerine odaklanmaya başlamıştır. O güne kadar pasif olarak görülen izleyici faktörü Katz'ın bakış açısından sonra medyayı belirli amaçları doğrultusunda kullanan aktif izleyici modeline dönüşmüştür. Kullanımlar ve Doyumlar Yaklaşımı'nda; kullanıcının özgür ve etkin olduğu, içerikleri kendisinin seçtiği, kendi ihtiyaçları doğrultusunda en iyi doyumu sağlayacak kitle iletişim aracına yöneldiği ve ihtiyacını giderdiği görüşü hakimdir (Fiske, 2003:199). Dolayısıyla Kullanımlar ve Doyumlar Yaklaşımı'na göre insanlar medyayı kendi gereksinimeleri doğrultusunda tüketmektedir. Medyanın nasıl ve ne ölçüde tüketildiği ancak izleyicinin gereksinmelerinden hareket edilerek ortaya çıkmaktadır. Yaklaşım özet olarak bir doyumun söz konusu olduğunu, buna dayalı olarak da bir kullanımdan bahsedilebileceğini, medya izleyici ilişkisinin de ancak bu yönüyle anlaşılabileceğini ileri sürmektedir.

Kullanımlar ve doyumlar yaklaşımı üzerine çalışan araştırmacılar genellikle insan ihtiyaçlarını sınıflandırmak üzerinde durmuşlardır. Konuya dair en ayrıntılı sınıflandırmayı Blumler, McQuail ve Brown'un çalışmalarında görmek mümkündür. Buna göre, oyalanma (eğlence), kişisel ilişkiler, kişisel kimlik ve gözetim sınıflandırması yapan araştırmacılar, kitlenin bunlardan hangilerini doyurma yoluna gittiğini araştırmıştır (Katz vd, 1973:513). Onlara göre medya bize rutinden kaçmak, problemlerden kurtulmak, endişeler veya gerilimlerden çıkmak, kitle iletişim araçlarıyla komşularımızdan daha çok birlikte olarak kişisel ilişkilerde etkileşim sürecine girmek, tartışmalara katılmak, medya karakterlerini ve yaşadıklarını kendi problemlerimizi çözmek için kullanmak gibi şekillerde etkide bulunmaktadır (Fiske, 2003:198-199). İzleyiciler bir eksiklik duygusundan yola çıkarak, kendi intiyaçlarını belirlemekte ve bu eksiklik temelli ihtiyaçlarını televizyon aracılığıyla tatmin etmeye çalışmaktadırlar.

Ortaya çıktığı zamanlarda kitle iletişim etki kuramları içinde izleyiciyi ön plana almasıyla dikkati çeken yaklaşım, iletişimcinin ve iletinin amacından çok, izleyicinin güdülerini, isteklerini, bunların doyurulmasını temel 
almaktadır. Bu nedenle günümüzde birçok bilim insanı tarafından sosyal psikolojideki gelişmeler çerçevesinde beklenti-değer yaklaşımı içinde gösterilse de yaklaşıma ilişkin kimi eleştiriler de mevcuttur. Bu eleştirilerin en önemlilerinden bir tanesi yaklaşımın çok fazla bireysel olduğu ve sosyal yapılarla ilişkilendirilmesinin zorluğuna işaret etmektedir (McQuail \& Windahl, 1993:115-116). Yine de internet kullanımının artması ve buna bağlı olarak sosyal medya araçlarının kullanımının yaygınlaşması ile yaklaşım yeniden önem kazanmıştır. Bunun en önemli nedenlerinden birisi sosyal medyanın etkileşim özelliğinin kullanıcıya vermiş olduğu aktif roldür. Kullanıcının, içerik oluşturma ve geliştirme alanındaki özgürlüğü, kontrol gücü bu yaklaşımın sosyal medya alanındaki araştırmalarda kullanımını kolaylaştırmaktadır (Quan-Haase \& Young, 2010:351).

\section{BIR SOSYAL MEDYA UYGULAMASI OLARAK SNAPCHAT}

Literatürde en çok atıf alan tanımlamalardan biri olan Boyd ve Ellison'nun tanımına göre sosyal medya; "kullanıcıların tamamen veya kısmen açık birer profil oluşturup, ilişkide oldukları insanlar listesi hazırladıkları, sergiledikleri, paylaştıkları ve diğer kullanııların profil ve ilişkilerini gözlemleyebildikleri sanal ortamlar"dır (Boyd \& Ellison, 2004; 211). Kaplan ve Haenlein ise farklı bir pencereden yaklaşarak sosyal medyayı "kullanıcı tarafından oluşturulan, içerik üretimine ve paylaşımına olanak veren, web 2.0'ın ideolojik ve teknolojik temelleri üzerine inşa edilmiş internet tabanlı uygulamalar grubu" biçiminde tanımlamışlardır (Kaplan \& Haenlein, 2010; 61). Her iki tanımlamada da benzeşen ve farklılaşan noktalar olsa da tanımlamaların temelini ağ üzerinde çalışan, web 2.0 altyapısına dayalı, etkileşimli uygulamalar oluşturmaktadır.

Sosyal ağların ve sosyal medyanın ortaya çıkışı ve popülaritesi ile binlerce kişinin tek bir bireymiş gibi birbirleriyle iletişim sağlamaları kolaylaşmıştır (Owen \& Humphrey, 2010:3). Bunun yanı sıra sosyal paylaşım siteleri yaş, din, politik görüş, hobiler ve ilgi alanları gibi kriterleri göz önüne alarak sınıflandırma ve etiketleme yapabilmektedirler. Bu sınıflandırma ve etiketleme ile gruplar arasında nasıl etkileşimlerin meydana geldiği araştırılabilmektedir (Maranto \& Barton, 2010: 36). Dolayısıyla, her ne kadar, farklı sosyal medya uygulamalarının hedef kitlesi, kullanım amacı, kullanım biçimi ya da yer aldığı platform farklılık gösterse de temel yapısı genellikle aynı mantık üzerine kurulmaktadır.

Bu çalışmanın konusunu oluşturan Snapchat de kendi doğasına, kullanım hedefine ve algoritmasına yönelik bir takım farklılıklar taşısa da tanımlamalardaki sosyal medya platformlarının genel özellikleriyle uyumludur.

Snapchat 2011 yılında üç Stanford Üniversitesi öğrencisi Evan Spiegel, Bobby Murphy ve Reggie Brown tarafından kurulan ve arkadaşlar arasında zaman kısıtlı fotoğraf/video paylaşımına izin veren gizlilik temelli mobil paylaşım uygulamasıdır (Snapchat, 2016). Uygulamayı benzerlerinden ayıran en önemli fark, kullanıcıların çektikleri ve "snap" adı verilen video ya da fotoğrafların karşı tarafça ne kadar süreyle görüntülenebileceğini belirleyebiliyor oluşudur. En fazla 10 saniyeye görüntüleme imkanı tanıyan uygulama, bu sürenin sonunda görüntüleri silmekte ve herhangi bir ekran görüntüsü alınması durumunda içerik sahibine haber vermektedir. Fakat diğer yandan, içeriğin Snapchat arayüzünden silinmesi dijital ortamdan ve Snapchat sunucularından silindiği anlamına gelmemektedir. Nitekim, Ekim 2014'te Snapchat sunucularının hacklenmesi ile birçok kullanıcının ve ünlünün silindi zannedilen fotoğrafları tüm internet alemine yayılmıştır. (Hürriyet)

Snapchat uygulaması hem bireysel hem de toplu halde snap gönderilmesine izin vermektedir. Kullanıcılar "stories" adı verilen snap örgüleri yaratarak fotoğraf ve videolarını tüm takipçilerin görebileceği biçimde paylaşabilmektedir. Öte yandan uygulama sayesinde kullanıcılar kimi eklentiler yardımıyla 
paylaşımlarını eğlenceli hale getirebilir ya da özel mesajlaşma servisi yardımıyla birbirlerine kısa mesajlar gönderebilmektedir (Dodson, 2015).

Popülaritesi hızla artan uygulamanın Nisan 2016 verilerine göre dünya genelinde 100 milyon aktif kullanıcısı bulunmaktadır. Tüm dünyada toplam sosyal medya kullanıcılarının \%18'i Snapchat kullanırken, saniyede ortalama 9 Bin snap atılmakta ve günde 10 milyon video izlenmektedir (Beck, 2016).

Gördüğü ilgi her geçen gün artan Snapchat sunduğu görüntülü ve sesli iletişim olanakları, görece güvenli sayılabilecek kullanım pratiği ve eğlence vaadleriyle tipik bir sosyal medya platform görünümündedir. Diğer yandan Sosyal medyayı diğer geleneksel medyadan ayıran en önemli özelliği kullanıcıların içerik oluşturma konusundaki aktif tutumları ve böylece etkileşimi mümkün kılmalarıdır. Tüketiciden üretici haline dönüşmesi "prosumer" haline gelmesi kullanıcıların kontrolü ellerine almaları anlamına da gelmektedir (Quan-Hasse ve Young, 2010:351). Bu haliyle Snapcaht de kullanıc beklentilerini fazlasıyla karşılayan bir uygulama olarak yoğun ilgi görmektedir.

\section{ARAŞTIRMA}

\section{Araştırmanın Amacı ve Kapsamı}

Bu çalışma, gençlerin günümüzün popüler sosyal medya uygulamalarından biri olan Snapchat kullanımında, tutum ve davranışlarını Kullanımlar ve Doyumlar Yaklaşımı bağlamında incelemeyi amaçlamaktadır.

Araştırma kapsamında gençlerin Snapchat kullanımında sergiledikleri tutumlar, kullanım amaçları, yöntemleri ve elde ettikleri doyumlar değerlendirilmeye çalışılmış ve genç kullanıcıların hangi amaç ve motivasyonlar ile bu uygulamayı kullandıkları incelenmiştir. Çalışma genç kullanıcıların hangi ihtiyaçları karşılığında hangi doyumları elde ettiklerine dair veriler sunmaktadır.

Söz konusu amaç ve kapsam bağlamında araştırmanın hipotezleri;

- Gençlerin Snapchat kullanımında temel doyum noktasını eğlence ve hoş vakit geçirme oluşturmaktadır.

- Kullanıcılar medyatik, ünlü insanların gündelim yaşamlarını merak etmektedir. Şeklinde belirlenmiştir.

\section{Araştırmanın Yöntemi}

Internet ve sosyal medya üzerine yerli ve yabancı literatürde oldukça fazla nicel araştırmaya rastlamak mümkündür fakat alana dair nitel araştırmaların azlığı da dikkat çekicidir. Bu alanda niteliksel araştırmanın az olması, araştırmanın önemine ve alanda elde edilen niteliksel verilerin gerekliliğine vurgu yapmaktadır. Nitel araştırmanın esnek ve bütüncül yaklaşımı, neden sorusuna cevap verirken, sosyal medya kullanıcılarının kullanımdan elde ettikleri doyumlar hakkında detaylı, kişisel, sübjektif, algı, duygu, düşünce ve deneyimlerine dair bilgiler sağlamaktadır (Ataseven, 2012: 546-548). Bu açıdan da değerlendirildiğinde, nitel bir araştırma yapmak önem taşımaktadır.

Bu çalışmada nitel araştırma yöntemlerinden biri olan derinlemesine mülakat yöntemi uygulanmıştır. Derinlemesine mülakat yüzeysel nicel verilerden çok araştırmaya denek olan bireylerin görüş, düşünce ve algılarıyla ilgili bilgi toplama amacını taşımaktadır (Altunışık vd., 2012:93). 
Uygulanan derinlemesine mülakatlar, kullanımlar ve doyumlar yaklaşımına ilişkin literatürde en geniş kapsamlı sayılabilecek Blumler, McQuail ve Brown'un sınıflandırılması üzerine kurulmuştur (Katz vd, 1973:513). Buna göre mülakat içerisinde, kullanıcıların uygulamadan elde ettikleri doyumu ve nedenlerini ölçmek amacıyla dört demografik, altı ucu kapalı ve 14 ucu açık toplam 24 soru tasarlanmıştır.

Çalışmada kullanılan 24 soru "Kullanım Tercihleri”, "Kullanım Sıklığı ve Erişim Aracı”, "Paylaşım İçeriği ve Nedenleri", "Takipçi Sayısı ve Profil (Snap) Güncelleme" başlıklarından oluşan dört kategoriye göre sınıflandırılmıştır. Sorulardan elde edilen yanıtlar Korgaonkar ve Wolin'in gerçekleştirdikleri araştırmalarda belirledikleri "Sosyal Etkileşim", "Bilgi Arama/Bilgiye Ulaşma/Bilgi Paylaşma", "Zaman Geçirme", Eğlence", "Rahatlama”, "Düşüncelerin Iffadesi”, "Kullanım Kolaylı̆ı̆”, "Gözetim", "Beğenilme/Takdir Edilme” doyum sınıfları bağlamında değerlendirilmiştir. (Korgaonkar \& Wolin, 1999:63)

\section{Araştırmanın Örneklemi ve Sınırlılıkları}

Yarı yapılandırılmış mülakatla katılımcıların Snapchat'e yönelik motivasyon ve doyumlarını ölçmek amacıyla yaşları 21-24 arasında değişen Marmara Üniversitesi dördüncü sınıf öğrencileri arasında uygulamayı düzenli olarak kullanan 25 öğrenci basit tesadüfi örneklem yöntemi ile belirlenmiştir. Bu örnekleme yönteminde evreni oluşturan her elemanın örneğe girme şansı eşittir. Bu yüzden hesaplamalarda da her elemana verilecek ağırlık aynıdır (Arıkan, 2004:141). Dolayısıyla örneklem seçiminde sadece öğrencilerin Snapchat uygulamasını kullanıyor olması şartı aranmıştır. Görüşmeler, 26.09.2016 ile 30.09.2016 tarihleri arasında Marmara Üniversitesi İletişim Fakültesi'nde gerçekleştirilmiştir. Ortalama 30 dakika süren görüşmeler kayıt cihazıyla kayda alınmış, sonrasında deşifre edilerek raporlanmıştır. Analiz çerçevesinde görüşmeleri daha net bir şekilde yansıtabilmek amacıyla doğrudan alıntılara yer verilmiştir. Tüm veriler sistematik bir şekilde betimlenmiştir. Bu betimlemeler açıklanmış yorumlanmış, neden sonuç ilişkileri araştırılmış ve sonuçlara ulaşılmıştır.

Araştırma belirli bir üniversitenin, belirli bir sınıfı ve belirli bir yaş aralığını temsil ettiğinden homojen bir grup yapısından söz etmemiz mümkündür. Öğrencilerin İletişim Fakültesi'nde eğitim görüyor olmaları, onların kitle iletişim araçlarına yaklaşımlarında ve kullanımlarında diğer fakültelerde okuyan öğrencilere nazaran belirli bir bilinç düzeyinde olmalarına ve araştırmanın sınırlı genellemelere ulaşmasına neden olabilmektedir.

\section{Bulgular}

Araştırmaya dair seçili öğrenciler ile 26.09 / 30.09.2016 tarihleri arasında gerçekleştirilen görüşmelerde deneklere (Tablo 1) öncelikle hangi sosyal medya araçlarını kullandıkları sorulmuş vee $n$ çok tercih ettikleri araçları sıralamaları istenmiştir. Ardından kullanım sıklıkları, erişim araçları, kullanırken neler yaptıkları, paylaşım içerikleri, nedenleri ve takipçi sayılarını içeren sorular yöneltilerek; özellikle Snapchat uygulamasını neden kullandıkları, hangi ihtiyaçlarını tatmin ettikleri ve beklenilen doyumlara ulaşılıp ulaşılmadığını belirtmeleri istenmiştir. İnsanların sosyal medyayı kullanım tercihi, bir sosyal medyayı diğerine tercih etmek ya da daha sıklıkla kullanmak veya kullanırken gerçekleştirilen eylemler, tutumlar, kullanım şekilleri, gerçekleştirilen paylaşımın içeriği, nedeni, her sosyal medyanın farklı olması nedeniyle hangi doyumu sağladıklarına yönelik bilgi verme konusunda önem taşımaktadır. Kullanım tercihi ve sıklığı, belirtilen sosyal medya aracına olan bağlılığı, paylaşım içeriği ve nedenleri kullanım ihtiyacını ve hangi doyumların sağlandığını ortaya koymaktadır. Takipçi veya arkadaş sayısına verilen önem de öğrencilerin kendilerini sosyal medyada ne derece tanıtmak istediklerine, popülerlik vasfına verdikleri öneme vurgu yapmaktadır. Snap güncelleme sıklığı da takipçilerine ya da arkadaşlarına kendileri hakkında güncellenmiş bilgi iletme ihtiyaçlarını belirtmektedir. Dolayısıyla betimsel analiz yapılırken, kullanım tercihleri, kullanım sıklığı ve erişim aracı, paylaşım içeriği ve 
nedenleri, takipçi sayısı ve snap güncelleme kategorilerinin belirlenmesi öğrencilerin bu araçları kullanımları ile elde ettikleri doyumları arasında bir anlamlandırma yapılması açısından önemlidir.

Tablo 1. 09 Mayıs / 13 Haziran Tarihleri arasında Görüşme Yapılan Öğrenciler.

\begin{tabular}{|l|l|l|l|}
\hline İsim & Bölüm & Cinsiyet & Yaş \\
\hline İrem A. & Gazetecilik & Kadın & 21 \\
\hline Beril & Gazetecilik & Kadın & 20 \\
\hline Utku & Radyo-TV ve Sinema & Erkek & 21 \\
\hline Aslı & Halkla İlişkiler ve Tanıtım & Kadın & 21 \\
\hline Pelin & Halkla İlişkiler ve Tanıtım & Kadın & 22 \\
\hline Barış & Radyo-TV ve Sinema & Erkek & 20 \\
\hline Zeynep & Gazetecilik & Kadın & 21 \\
\hline Nihat & Radyo-TV ve Sinema & Erkek & 22 \\
\hline Serhan & Halkla İlişkiler ve Tanıtım & Erkek & 21 \\
\hline Hülya & Gazetecilik & Kadın & 24 \\
\hline Cem & Halkla İlişkiler ve Tanıtım & Erkek & 24 \\
\hline Mustafa & Halkla İlişkiler ve Tanıtım & Erkek & 23 \\
\hline Gizem & Radyo-TV ve Sinema & Kadın & 21 \\
\hline Mücahit & Gazetecilik & Erkek & 23 \\
\hline Damla & Gazetecilik & Kadın & 23 \\
\hline Sümeyye & Radyo-TV ve Sinema & Kadın & 22 \\
\hline Yusuf & Radyo-TV ve Sinema & Erkek & 21 \\
\hline Muhammet & Halkla İlişkiler ve Tanıtım & Erkek & 23 \\
\hline İrem K. & Gazetecilik & Kadın & 22 \\
\hline Gülşen & Gazetecilik & Kadın & 22 \\
\hline Ozan & Halkla İlişkiler ve Tanıtım & Erkek & 23 \\
\hline Hatice & Radyo-TV ve Sinema & Kadın & 23 \\
\hline Esat & Halkla İlişkiler ve Tanıtım & Erkek & 22 \\
\hline Kadir & Radyo-TV ve Sinema & Erkek & 23 \\
\hline Büşra & Gazetecilik & Kadın & 21 \\
\hline & & & \\
\hline
\end{tabular}

Sorulan sorular ve elde edilen yanıtlar çerçevesinde sosyal medya araçlarının kullanımına yönelik kimi ortak sonuçlara ulaşılmıştır. Öğrencilerin tümü Facebook, Twitter ve Instagram hesaplarına sahip olmakla birlikte aynı zamanda Snapchat kullandıklarını da belirtmişlerdir. Gerçekleştirilen görüşmeye göre öğrencilerin tamamı hergün sosyal medya uygulamalarına girdiklerini, paylaşım yapmasalar bile günde en az iki ya da üç kez control ettiklerini, içerikleri okuduklarını belirtmişlerdir. Öğrencilerin tamamının akıllı telefon sahibi oldukları ve sosyal medyaya sıklıkla bu akıllı telefonları kullanarak girdiklerini ifade etmiştir. Öğrenciler arasında sosyal medyayı kullanım tercihleri konusunda da zamana bağlı değişimler gözlenmiştir. Öğrenciler zaman içinde Facebook ve Twitter'ı daha az kullanmaya başladıklarını Snapchat ve Instagram kullanımlarının ise arttığını ifade etmişlerdir. Öğrencilere göre Facebook demode hale gelirken özellikle görsel içeriklerin yoğun olarak kullanıldığı Instagram ve Snapchat popüler araçlar konumundadır. Snapchat ve diğer popüler sosyal medya araçlarının kullanımına ilişkin farklılıklar şu şekildedir.

Öğrenciler Facebook'u arkadaşları ile chat programı üzerinden sohpet etmek, kişiler hakkında detaylı bilgi edinmek (stalklamak, gözetlemek), çeşitli gruplara üye olmak, etkinlikleri takip etmek ve etkinlik düzenlemek ile mizah içerikli paylaşımda bulunmak amacıyla kullandıklarını belirtmişlerdir. Sık kullanılan diğer araçlardan olan Twitter'ı ise gündeme ilişkin bilgi almak, siyasi olayları takip etmek, kanaat önderi olarak 
tanımladıkları bireylerin düşüncelerini öğrenmek, gündeme ilişkin veya kişisel düşüncelerini ifade etmek, haber sitelerine ait hesapları takip etmek amacıyla kullanmaktadırlar. Instagram'ı ise diğer kullanıcıların fotoğraflarına bakmak, kendilerine ait fotoğrafları ya da kendi çektikleri fotoğrafları paylaşmak, hobi hesaplarını izlemek ve kişiler hakkında bilgi sahibi olmak amacıyla kullandıklarını belirtmişlerdir.

Çalışmamızın konusunu oluşturan ve son zamanlarda popülerliği artan Snapchat için ise gün içinde yaşadıkları ilginç anları veya karşılaştıkları nesneleri paylaşmak, Selfie çekmek, snapchat filtreleri ile kısa videolar çekmek ve bunlardan hikayeler oluşturmak ve mesaj özelliği ile sohbet etmek ifadelerini kullanmışlardır.

\section{Kullanım Tercihleri}

Elde edilen yanıtlar üzerinden kullanım tercihlerine ilişkin genel bir değerlendirme yapılacak olursa öğrencilerin sosyal ağ tercihlerini yaparken kullanım rahatığı, erişim kolaylığı, eğlence, sosyalleşme, yaşamlarını paylaşma ve popülerlik gibi olgulara dikkat ettikleri söylenebilir. Snapchat için ise öne çıkan temel tercihin eğlence ve boş vakit geçirme ve fotoğraf paylaşmak olduğu görülmektedir. Öğrencilere göre snapchat tercihindeki temel unsurlardan biri de basit arayüzü ve kullanıcı dostu olması. Görüşülen öğrencilerden Barış bu düşüncesini;

"Snapchat'in arayüz tasarımı oldukça basit. Adeta 'hadi bişiler çek ve paylaş' etkisi yaratıyor"

sözleriyle ifade ederken bir diğer öğrenci Utku ise,

“Çektiğim videoların üzerine yazı eklemek için farklı bir programa ihtiyacım yok. Hepsi içinde. Aynı zamanda videolarımı çekip, saklayıp daha sonra da paylaşabiliyorum. Mesela Instagram'da bu yok."

şeklinde özetlemiştir. Diğer yandan arayüz tasarımını kullanım tercihi olarak niteleyen öğrencilerin tamamının erkek olması da bir başka ilginç noktadır.

Öğrencilerin birçoğu için mecranın popülerliği de kullanım tercihini belirleyen önemli unsurlar arasında. Son zamanların popüler uygulamaları olan Instagram ve Snapchat arasında da bir rekabet söz konusu. Bu yüzden Snapchat'in kullanım farklılığına olan ilgiyi farkeden Instagram, kendi içinde benzer bir yeniliği uygulaması içine entegre etmekte geç kalmadı. Kullanıcılar artık Instagram’ı da Snapchat gibi kullanabiliyorlar. Fakat öğrencilere göre Snapcaht kullanımı hala revaçta görünüyor. Görüşmeye katılan öğrencilerden Hatice bu durumu,

"Arkadaşlarımın birçoğu Snapchat kullanıyor. Hatta Instagram paylaşımları azaldı, Snap'leri arttı. Aslında herkes ne kullanıyorsa biz de yükleyip kullanmaya başlıyoruz."

Sözleriyle ifade ederken bir diğer öğrenci Büşra ise

"Muhtemelen Snapchat'in de modası geçecek ama şu an kullanmayan yok. Kimse de olup bitenden geri kalmak istemiyor"

şeklinde popüler kullanıma vurgu yapmıştır. Kullanım tercihini belirleyen unsurların başında da Snapchat'in görsellere ilişkin süre kısıtlaması gelmektedir. Snapchat video ya da fotoğraf paylaşımlarında kullanıcının görme süresini ayarlayabilmesine olanak tanırken bu sürenin sonunda içerikler silinmektedir. 
Herhangi bir kullanıcının ekran görüntüsü alması durumunda ise içerik sahibine kimin aldığına ilişkin bildirim gitmektedir. Birçok öğrencinin bu durumu güvenlikle bağdaştırması dikkat çekicidir.

"Fotoğrafımı kimin ne kadar süreyle görebileceğine ben karar veriyorum. Misal Instagram'da arkadaşın olan herkes görüyorken Snapchat'te bu kişileri ve görme süresini belirleyebiliyorsun. Ekran görüntüsü de alamıyorlar. Böylece fotoğraflarım elde ele gezmiyor. Bu bir güvenlik önlemi değil mi?"

sözleriyle ifade eden Hülya'nın yanısıra Serhan adlı öğrenci ise benzer düşüncelerini,

"Fotoğrafın karşı tarafın ekranından silinmesi bence güvenli bir durum. Sonuçta bazen fotoğrafların sadece görünmesini istiyoruz saklanmasını değil."

şeklinde dile getirmiştir. Güvenlik ve dolayısıyla mahremiyet üzerine düşünceleri belirleyen temel unsurlardan birinin de rahatlık hissi olduğu görüşmelerde elde edilen bulgulardan biridir. Öğrenciler güvenli buldukları platformları daha rahat ve huzurlu kullandıklarını ifade etmişlerdir. İrem A. bu duruma ilişkin,

"Kimlerin neyi ne ölçüde görebileceğini belirlemek beni iyi ve rahat hissettiriyor. Kimi arkadaşlarıma günde 5-6 snap atarken kimisine hiç atmıyorum. Dolayısıyla içerikler de değişiyor. Gerçi bu özellik Facebook'ta da var ama orda çok fazla ayarla uğraşmak lazım. Bir de koyduğunuz bir fotoğraf ya da yazı yıllar sonra karşınıza çıkıyor. Bu anlık. Atıyorsun geçiyorsun."

ifadelerini kullanırken Beril aynı konuda,

"Fotoğrafın silinmesi çok güzel birşey. Instagram'da bu kadar fotoğraf paylaşsam insanlar sıkılıp beni siler. Ama burda bakıyorlar, birdaha görmüyorlar. Açıkçası bu paylaşım için beni cesaretlendiriyor."

yorumunu yapmıştır. Öne çıkan bir diğer kullanım tercihi ise eğlence ve eğlence ihtiyacıdır. Öğrencilere göre Snapchat eğlenceli bir platform olarak diğerlerine göre fark yaratmaktadır.

"Fotoğraflar üzerinde şekiller çizerek ya da boyayark değişiklikler yapabiliyorsun bu oldukça eğlenceli bir durum. Ben sıklıkla kendi selfilerime bu tarz eklemeler yapıyorum, çok komik olduğuna ilişkin de tepkiler alıyorum arkadaşlarımdan"

sözleriyle eğlenceye vurgu yapan Yusuf'un yanı sıra Damla da benzer düşüncelerini şu sözlerle ifade etmiştir.

"Snapchat'in bazı şablonları var. Bunları kendi fotoğraflarıma uygulayarak oldukça eğlenceli içerikler ve hikayeler yaratabiliyoruz. Sonuçta bu platformlar niye var? Ben gün içinde bunları izleyerek rahatlıyorum, kafamı dağıtıyorum."

Eğlence konusunda Snapchat'in diğer platformlara göre bir adım öne çıktığını belirten Pelin bu durumu,

"Facebook oldukça sıkıcılaştı, bütüm ailem neredeyse orada. Twitter ise ülke gündemini takip etmek için iyi ama sonuçta gündem de malum. O yüzden Instagram ve Snapchat daha iyi. Akşamları insanların paylaşımlarını izliyorum, videolarını seyrediyorum. Hem onlar gün içinde neler yapmış ögreniyorum hem de gülüyorum." şeklinde özetlemiştir. 
Birçok öğrencinin sosyal medyayı genel olarak eğlence amacıyla kullanmaları ya da temel beklentilerinin başında eğlence ve rahatlama ihtiyacının gelmesi de altı çizilmesi gereken noktalardan bir tanesidir.

\section{Takipçiler ve iç̧erik (Snap) Güncelleme}

Snapchat diğer profillere göre takipçi sayısını diğer kişilere göstermeyen nadir uygulamalardandır. Uygulama Facebookla benzer biçimde takip edenin geri takip edilmesi esasına dayanmaktadır. Karşlıklı takip edilmediği sürece Snaplar görüntülenememektedir. Uygulamanın kullanıcıları da diğer kişilerin kaç takipçisi olduğunu görememektedirler. Aslı'ya göre uygulamanın bu hali insanların saplantılarını ortadan kaldırmaktadır.

"Snapchat'te takipçi sayılarımızı kimse göremiyor. Bu yüzden mesela takipçi kasma gibi birşey yok. Kimse takipçi sayısını arttırmak için olur olmaz snapler atmıyor. Daha doğal, içinden geldiği gibi davranıyor. Şu takipçi saplantısından kurtulduk."

Kadir ise takipçi konusundaki düşüncelerini,

"Beni kimin takip ettiği, takibi bırakıp bırakmadığı gibi konular önem taşımıyor. Örneğin ben kaç takipçim var bilmiyorum. Programı açıp saymam lazım. Öyle sayıyla gösteren bi yer yok uygulamada. Önemli olan seçtiğin insanlarla keyifli vakit geçirmek. Sonuçta hepsi tanıdığım insanlar."

Sözleriyle dile getirmiştir. İçeriklerin güncellenme aralı̆̆ ise takipçi sayısına göre öğrenciler için çok daha fazla önem taşımaktadır. Bu konudaki genel kanı sıkııı olmaması yönündedir. Fazla miktarda içerik paylaşımının sıkıcı olduğu, bu konuda bir denge tutturulması gerektiği öğrencilerin geneline hakim olan düşüncedir. Zeynep’e bu durumu,

"Sonuçta bunu eğlenmek için kullanıyorum. Aynı kişiden sürekli içerik almak bir yerden sonra beni sıkar. Hergün aynı yemeği yemek gibi birşey bu. Biraz da saygısızca. Snapchat'e ayırdığım şey de bir vakit. Vaktimi çalmamalılar." sözleriyle ifade ederken, Gizem ise,

"Bazen sürekli aynı kişiden tonla snap alıyorum. Sabah kalkıp gece yatana kadar snap atıyor mesela. Bu beni yoruyor. Farklı şeyler de görmek istiyorum. Sürekli ben ben diyen biri gibi. Egosantrik bi durum. Bu kişileri bir süre sonra engelliyorum." sözleriyle snap güncelleme sıklığının ego kavramıyla ilişkili olabileceğini düşünmektedir.

\section{Kullanım Aralığı ve Kullanım Aracı}

Öğrenciler Snapchat dışındaki Facebook, Twitter gibi sosyal medya araçlarını hergün mutlaka ziyaret ettiklerini fakat bunların belirli zaman dilimlerine odaklandığını belirtirken Snapchat' $i$ ise telefonu ellerine her aldıklarında bakma ihtiyacı hissettiklerini ifade etmişlerdir. Bu konuda Cem düşüncelerini,

"Facebook'a günde 1-2 kez giriyorum. Twitter'a belki daha fazla. Ama Snapchat sürekli elimin altında. Hem izliyorum hem Snap atıyorum." Sözleriyle ifade ederken Mücahit ise,

"Her dakika bir snap güncellemesi geliyor. Mutlaka birisi birşey paylaşmış oluyor. Derste sıkıldığım zaman bile bunlara bakıyorum. Bu aralar en çok Snapchat kullanıyorum diyebilirim." diyerek düşüncelerini dile getirmiştir.

Erişim aracı kullanımı ise tüm öğrenciler için mobil telefonlardır. Snapchat'in bir web versiyonunun olmayışı en önemli sebebi oluştururken Ozan bu durummun zaten uygulamanın doğası gereği olduğunu düşünmektedir. 
"Bu anı kaydedeceğiniz bir uygulama. Facebook ya da Twitter gibimasa başında anlarınızı paylaşamazsınız. O zaman kurgusal olur. Snapchat sokakta, otobüste, konserde kullanmak için. Mobil olmak dışında başka alternatifi olamazdı zaten."

Zamanın ve mekanın yöndeşmesi bağlamında mobil teknolojilere vurgu yapan Ozan'nın dışında Muhammet ise kullanım açısından tek alternatifin mobil cihazlar olması dışında bu cihazların teknolojik gelişim düzeylerinin de kullanım sıklığını arttırdığını savunmaktadır. Muhammet,

"Bu akıllı telefonların teknolojileri de insanları kullanıma itiyor aslında. Şimdi hepsinin ön kamerası var ve çözünürlükleri yükseliyor. Bizden çekip paylaşmamızı bekliyor gibiler." sözleriyle aracın teknolojik gelişmişliğine vurgu yapmaktadır.

\section{Paylaşım İçeriği ve Sebepleri}

Görüşmelerden elde edilen bulgulara göre, paylaşımın içeriği hemen hemen tüm öğrencileri için kullanım ve doyumun derecesini belirleyen temel kriterlerden biridir. Öğrencilerin büyük çoğunluğu Facebook, Twitter gibi görece daha eski uygulamaları bilgi edinmek, iletişim kurmak, gündemi takip etmek gibi ihtiyaçlarını karşılamak üzere girdiklerini beyan ederken Snapchat için ise temel ihtiyaç motivasyonlarını "eğlence" olarak belirledikleri gözlemlenmiştir. Dolayısıyla öğrencilerin platformda içeriklerden beklentileri de bu ihtiyaçlar çerçevesinde şekillenmektedir. Eğlence dışında bir diğer kullanım alternatifi de çevrelerindeki "insanların gündelik hayatlarından haberdar olma" durumudur. Görüşmeye katılan öğrencilerden Sümeyye,

"Arkadaşlarımla sürekli birlikte değilim. En azından burden gün içinde nerde ve ne yaptıklarını görebiliyorum" derken Nihat, "Bazen bir arkadaşımı merak ettiğimde aramak yerine önce Snaplerini control ediyorum" diyerek gündelik hayata ilişkin içeriklerin önemine vurgu yapmıştır.

Ülke ve dünya gündeminin sıkıcılığından kaçıp nefes almak için eğlence aradıklarını ifade eden öğrenciler, Facebook ve Twitter'ın gündeme ilişkin boğuculuğundan kaçmak için Snapchat içeriklerini bir alternatif eğlence aracı olarak gördüklerini ifade etmişlerdir. Nihat'a göre snapleri izlemesindeki temel belirleyicinin eğlenceli içerikler olması iken medyatik insanları da sırf bu sebepten takip ettiğini dile getirmiştir. Esat da konuya benzer bir vurgu yaparak,

"Bazen çevremdekilerin içerikleri sıkıcılaştığında yerli yabancı ünlüleri ve snap fenomenlerini izliyorum. Kafamı dağıtıyorum" diyerek düşüncelerini paylaşmıştır.

Eğlence konusunda Snapchat'in kullanıcılara oldukça fazla imkan tanıdığını belirten öğrenciler, uygulamanın çekilen video ve fotoğraflar üzerinde şekil çizmeye ve yazı yazmaya imkan tanıyan mimari yapısının yaratıcılığı da körüklediğini vurgulamışlardır. Komik ve eğlence bağlamında yaratıcı içeriklerin ilgi çektiğini vurgulayan öğrencilerden İrem A.,

"Bazen öyle güzel çizimler, videoya entegre edilmiş şekiller, hikayeler görüyorum ki. Aslında gerçek mizah böyle birşey." sözlerini sarf ederken, Gülşen de hem komik hem de yaratıcı içerikler üretmek için platform başında bazen uzun zaman harcadığını belirtmiştir. 
İçeriği belirleyen unsurlardan bir diğeri de kullanıcıların duygu durumlarıdır. Öğrenciler, sevinç, mutluluk, huzur gibi duygularını paylaşmaktan ya da insanların bu duygularını yansıtan içerikleri izlemekten keyif aldıklarını vurgularken tam aksi duyguların sıkıcı geldiğini ve bu tarz içerikleri paylaşmadıklarını belirtmişlerdir. Zeynep bu konuda,

\begin{abstract}
"Sonuçta eğlenmek için kullanıyorum. Biri mutluysa, gülüyorsa ben de gülebilirim. Doğum günümde saatlerce saatlerce snap attım. Çok da güzel tepkiler aldım. Insanlar da mutlu olmuşlar. Ben ağlayan birinin snapini izlemek istemem. Ya da öfkeli birinin siyasi içerikli snaplerini görmek istemem. Onun mecraları başka." sözlerini sarf ederken Mustafa,

"Mutsuz olduğumda bunu başkalarının bilmesine gerek yok. Ayrıca mutsuzluğumun giderilmesi gerekirken daha kederli şeyler izlemek istemem" şeklinde düşüncelerini ifade etmiştir.
\end{abstract}

Selfie çekmek de öğrencilerin içeriklerinde önemli bir yer tutmaktadır. Kimi öğrenciler kendilerini güzel/yakışıklı, bakımlı, mutlu hissettiklerinde bunu diğer insanlarla paylaşmanın kendilerini daha da iyi hissettirdiğini ifade ederken kimileri de anı paylaşmak amacıyla selfie çektiklerini belirtmişlerdir. Pelin adlı öğrenci aslında bunun bir alışkanlık haline geldiğini ve her sabah uyanınca ritüel gibi "günaydın" yazısıyla selfie snapi attığını belirtirken Utku bu konuda,

"Kendimi mutlu ve keyifli hissettiğimde bunu insanlarla paylaşıyorum. Hele de olumlu yorumlar alırsam kendime güvenim daha da artıyor" sözleriyle olumlu yorumlar ile özgüven arasındaki ilişkiye atıfta bulunmuştur.

Snapchat sadece o snapleri izleyenleri gösteren fakat Facebook ya da Instagram'da olduğu gibi herhangi bir beğeni (Like) butonunun olmadığı bir tasarıma sahiptir. Bu yüzden görüşmeye katılan öğrenciler için programın yazılı mesaj servisinden gelen yorumların beğeni (Like) gibi bir feedback olarak değerlendirildiği tespit edilmiştir. Öğrencilerden Hatice'ye göre beğeni butonu olmadığı için yorumla geri dönüş almak benzer içeriklerin devamı konusunda bireyi cesaretlendirmektedir. Selfie'lerini bir "sahne" olarak değerlendiren Zeynep ise, "Aslında hepimiz kendi halkla ilişkilerimizi yürütüyoruz. Doğal olmaya çalışsak da kimilerimiz doğal değil" sözleriyle içeriklerdeki kurgusallığa vurgu yapmıştır.

Snapchat My Story (Hikayem) özelliği ile gruplar oluşturup o gruplara özel içerikler ürettiğini belirten öğrenciler, grubu oluşturan kişilerin ortak özelliklerinin paylaşımın içeriğini de belirlediğini ifade etmişlerdir. Utku grubu oluşturan kişilerin ortak özelliklerinin içeriklerini belirlediğini,

"Ben Galatasaray'ıyım. Benim takımımı tutan kişilerden oluşturduğum gruba gittiğim maçlardan çekilmiş görüntüleri paylaşıyorum. Mesela sınıftaki arkadaşlardan oluşan bir grubumuz da var. Orada ise ders notlarını ya da hocaların sunum fotoğrafıarını atıyoruz." sözleriyle açıklamıştır. 


\section{DEĞERLENDIRME VE SONUÇ}

Gençlerin Snapchat kullanım nedenleri ve karşılığında elde ettikleri doyumları belirlemeye yönelik tasarlanan bu araştırma çerçevesinde Marmara Üniversitesi İletişim Fakültesi öğrencileri üzerinde odak grup çalışması gerçekleştirilmiştir. Kullanımlar ve Doyumlar Yaklaşımı bağlamında şekillenen araştırmada 25 öğrenciye kullanım tercihleri, kullanım sıklıkları, erişim şekilleri, paylaşım içeriği ve nedenleri, takipçi sayıları ve profil güncelleme kategorilerinde 24 soru sorulmuş ve yanıtlar Korgaonkar ve Wolin'in (1999) belirlediği sosyal etkileşim, bilgi arama/bilgiye ulaşma/bilgi paylaşma, zaman geçirme, eğlence, rahatlama, düşüncelerin ifadesi, kullanım kolaylığı, gözetim, beğenilme/takdir edilme doyum sınıfları bağlamında değerlendirilmiştir.

Görüşmeye katılan öğrencilerin Snapchat kullanım tercihlerini belirleyen unsurların başında, eğlence ve hoş vakit geçirme gelmektedir. Öğrenciler gündelik hayatın sıkıntısından kurtulmak amacıyla bu uygulamaya yöneldiklerini ifade etmişlerdir. Diğer yandan Facebook, Twitter gibi uygulamaların ise gün geçtikçe gündem konularına boğularak sıkıcılaştığını belirtmişlerdir. Farklı bir bakış açısıyla Snapchat'e yönelen yoğun kullanımı, öğrencilerin bu platform ülke ve dünya gündeminden bir kaçış aracı olarak görmeleri şeklinde de değerlendirmek mümkündür. Öğrenciler, hüzün, üzüntü ve dramadan kaçınmak için bu platformu tercih ettiklerini ve hem kendi mutlu anlarını hem de başkalarının mutlu anlarını izlemenin eğlenceli ve keyifli olduğunu öne sürmektedir. Mutluluk ihtiyacının sosyal ağlar yoluyla giderilmeye çalışılması dikkat çekici bir durumdur.

Kullanım tercihlerini belirleyen önemli unsurlardan bir tanesi de mecranın gün geçtikçe popülerleşmesi ve kullanımının yaygınlaşmasıdır. Çevre tarafından sıklıkla kullanılan yeni ve popüler bir uygulama, öğrencilerin çevreye uyum sağlama, onlarla iletişim kurma, moda olanı takip etme ve topluma uyum sağlama konusunda dikkatli ve hevesli olduklarını da göstermektedir. Moda kavramı sıklıkla değişebilen bir olgu olduğuna göre bu platformun da popülerlik süresi zaman içinde dolacak, başka bir platform gençler için ilgi odağı haline gelecektir.

Platformun video ve fotoğraflardan oluşan ve görselliği öne çıkarak kurgusu da öğrencilerin tercihleri belirleyen faktörler arasındadır. Hemen hemen hepsinin $Y$ kuşağını temsil ettiği öğrenci grubunun görselliğe ilgisi şaşırtıcı değildir. Tahtada yazan ders notlarının bile fotoğrafını çeken bu kuşak aynı zamanda dersleri de video ve ses kaydına almaktadır. Tercih ettikleri platformun bu özelliklerinin öne çıkması şaşırtıcı değildir. Öte yandan öğrencilere göre platformun kullanıcı dostu, basit arayüz tasarımı da kullanımı belirleyen faktörlerdendir. Zaman ve hız konusunda hassas olduklarını belirten öğrenciler hayatı ve anı yakalamak için araçların kullanımı kolay olmaları gerektiğini ifade etmişlerdir.

Başka insanların gündelik hayatlarını takip etmek ve haberdar olmak da platforumun kullanımını belirleyen önemli unsurlar arasındadır. Sevdikleri ünlülerin, takip ettikleri insanların, arkadaşlarının hayatlarından anlık olarak haberdar olmak isteyen öğrencilerin aynı zamanda bir tür gözetleme eğilimi içinde oldukları da söylenebilir. Instagram gibi görsel öğelerin öne çıktığı diğer uygulamaların kurgul olabileceğine vurgu yapan öğrenciler, Snapchat'in doğal hayat akışını yansıttığını düşünmektedir. Bu açıdan platform, takip edilen diğer insanları daha gerçekçi, reel ve içimizden biri haline getirmektedir. Öğrenciler gerçekliği kurgusallığa tercih etmektedir. Fakat öte yandan kendi snapchat hesaplarını birer sahne olarak da nitelemektedirler. Bu noktada gerçeklik arayışı ile sahnenin kurgusallığı bir çelişki yaratmaktadır. Takip ettikleri insanlardan en doğal hallerini talep eden öğrenciler, kendi paylaşımlarında kurgusallığa başvurabilmektedir. 
Snapchat kullanım tercihini belirleyen unsurlardan bir diğeri de platformun güvenlik vaatleridir. Snapchat, gönderilen snapleri kimlerin ne süreyle görebileceğini belirleme imkanı tanımaktadır. Gönderilen snapler içeriği hazırlayanın belirlediği süre sonunda silinmektedir. Platformun bu yapısının öğrenciler arasında "güvenli ortam" algısı yarattığı gözlemlenmiştir. Öğrenciler Instagram ya da Facebook gibi ortamlarda paylaşmaya çekindikleri içerikleri Snapchat'te daha rahat paylaştıklarını ifade etmişlerdir. Bu bağlamda kullanıcılar arasında sosyal ağlar genelinde bir güvenlik endişesi olduğundan söz edilebilir. Bu durum paylaşımların içeriğini ve sıklığını etkileyebilir. Fakat içeriğin Snapchat arayüzünden silinmesi dijital ortamdan ve Snapchat sunucularından silindiği anlamına gelmemektedir. Hatta ironik biçimde, ortaya atılan bu güvenlik algısı kullanıcıların, mahrem alanlarını sergilemede daha cesur davranmalarına sebep olmaktadır.

Literatür araştırmaları ve öğrencilerle yapılan odak grup görüşmeleri neticesinde elde edilen bulgular Korgaonkar ve Wolin'in (1999) doyum sınıflaması bağlamında değerlendirildiğinde; snapchat öğrenciler açısından eğlenme, kullanım rahatlığı, rahatlama, bilgi paylaşma, sosyal etkileşim, beğenilme/takdir edilme, gözetleme doyumlarını sağlamaktadır.

Genel olarak Kullanımlar ve Doyumlar Yaklaşımı bireylerin kimi eksikliklerini birer ihtiyaç olarak görerek bu ihtiyacı giderme yoluna gittiklerini; bu ihtiyacı gidermek için en etkin yol olarak kitle iletişim araçlarını gördüklerini ifade etmektedir. Illetişim teknolojilerinde yaşanan gelişmeler ve yeni medya ile birlikte sosyal paylaşım ağları da bireylerin ihtiyaçlarını gidermede kullandıkları araçlar haline gelmiştir. Snapchat özelinde gerçekleştirilen bu çalışma ile gençlerin, sosyal medya araçlarına bu eksikliklerini gidermek maksadıyla yöneldikleri de görülmektedir. İletişimin doğasının değişimi ile birlikte sosyal medya araçları yeni kullanımlar ve yeni doyumların kapısını aralasa da aracın yapısı değişse de kullanım biçiminin aynı kaldığı, değişmediği ortaya çıkmıştır.

\section{Kaynakça}

Alikılıç, Ö., Gülay, G., Binbir, S. (2013), “Kullanımlar ve Doyumlar Kuramı Çerçevesinde Facebook Uygulamalarının İncelenmesi: Yaşar Üniversitesi Öğrencileri Üzerine Bir Araştırma”, Illetişim Kuram ve Araştırma Dergisi, Sayı 37 / Güz, pp. 40-67.

Altunışık, R., Coşkun, R., Bayraktaroğlu, S. Yıldırım, En. (2012), Sosyal Bilimlerde Araştırma Yöntemleri, Sakarya Yayıncılık, Sakarya.

Arıkan, R. (2004), Araştırma Teknikleri ve Rapor Hazırlama, Asil Yayınları, Ankara.

Ataseven, B. (2012). "Nitel Bilimsel Araştırmalarda Veri Kalitesinin Önemi”, Marmara Üniversitesi, i.i. B. Dergisi, 2012, Cilt XXXIII, Sayı II, s. 543-564.

Beck, K. (2016). "Snapchat users are watching 10 billion videos a day", Mashable, April 28, 2016. http://mashable.com/2016/04/28/snapchat-video-views-billion/\#mqbUccgQ_Gq3 [26.07.2016]

Boyd, D., Ellison, J. (2004), "Social Network Sites: Definition, History and Scholarship", Journal of Computer-Mediated Communication, 13.

Chou, C., Hsiao, M. C. (2000). “Internet Addiction, Usage, Gratification, and Pleasure Experience: The Taiwan College Students' Case", Computers and Education, 35, 65-80.

Defleur, M. L., Dennis, E. (2002). Understanding Mass Communication: A Liberal Arts Perspective, USA: Houghton Mifflin College Div.

Dodson, P.C., (2015), "Why Snapchat's Live Stories Are The Most Powerful New Social Media", FastCompany, http://www.fastcompany.com/3052322/why-snapchats-live-stories-are-the-mostpowerful-new-social-media [26.07.2016]

Erdoğan, İ., Alemdar, K. (2010), Öteki Kuram, Erk Yayınları: Ankara.

Eighmey, J., McCord, L. (1998). “Adding value in the Information Age: Uses and Gratifications of Sites on the World Wide Web", Journal of Business Research, 41, pp.187-194. 
Fiske, J. (2003). Iletişim Çalışmalarına Giriş. Çev. Süleyman İrvan. Bilim ve Sanat Yayınları: Ankara.

Hermes J (2002) "Active Audiences", Adam Briggs, Paul Cobley (ed), The Media, Second Edition, Pearson Education Limited, Great Britain, pp. 282-293.

Jensen, K. B. ve Rosengren, K. E. (2007), "Five Traditions in Search of the Audience", D McQuail, P Golding, Els de Bens (eds), Communication Theory \& Research, Sage Publications, Great Britain, pp. 53-70.

Kaye, B.K., Johnson, T.J. (2002), "Online and in the know: uses and gratifications of the web for political information", Journal of Broadcasting \& Electronic Media, Vol. 46 No. 1, pp. 54-71.

Kaplan A. M., Haenlein M. (2010), "Users of the World, Unite! The Challenges and Opportunities of Social Media", Business Horizons, Vol. 53, Issue 1.

Katz, E., Blumler, J. G., Gurevitch, M., (1974). "Uses and Gratifications Research", The Public Opinion Quarterly, Vol. 37, No.4 (Winter, 1973-1974), pp.509-523 by Oxford University Press. http://www.jstor.org/stable/274785413. [26.07.2016]

Korgaonkar, P.K., Wolin, L.D. (1999). “A multivariaten Analysis of Web Uses”, Journal of Advertising Research, Vol. 39 No. 1, pp. 53-68.

Maranto, G., Mat B. (2010). "Paradox and Promise: MySpace, Facebook, and the Sociopolitics of Social Networking in the Writing Classroom", Computers and Composition, 27, pp.36-47.

Namsu Park, M.A., Kerk F. Kee, M.A., Sebastian V. (2009), "Being Immersed in Social Networking Environment: Facebook Groups, Uses and Gratifications and Social Outcomes", Cyberpsychology \& Behavior, Volume 12, Number 6, pp.729-733.

McQuail D., Windahı S. (1993). Iletişim Modelleri, Çev:Mehmet Küçükkurt, İmaj Yayınları, Ankara.

Owen, R., Patrica H. (2010). "The structure of Online Marketing Communication Channels", Journal of Management and Marketing Research, pp.1-10.

Quan-Hasse, A., Young, A. (2010). "Uses and Gratifications of Social Media: A Comparison of Facebook and Instant Messaging", Bulletin of Science, Technology \& Society, 30(5), Sage Publications, 350361.

Rigel, N., Batuş, G.,Yücedoğan, G., Çoban, B. (Ed.) (2005). Kadife Karanlık: McLuhan, Foucault, Chomsky, Baudrillard, Postman, Lacan, Zizek, Su Yayınları: İstanbul.

Snapchat. (2016), "Terms of Service”, https://www.snapchat.com/terms [26.07.2016]

Timisi, N. (2003). Yeni Iletişim Teknolojileri ve Demokrasi. 1. Baskı. Dost Kitabevi: Ankara. 